\title{
Sistem Sensor Gas Elektrokimia yang Diimplementasikan pada Arduino Due
}

\author{
Andrianto dan Muhammad Rivai \\ Departemen Teknik Elektro, Fakultas Teknologi Elektro, Institut Teknologi Sepuluh Nopember (ITS) \\ e-mail:muhammad_rivai@ee.its.ac.id
}

\begin{abstract}
Abstrak - Polusi udara pada wilayah perkotaan di Indonesia mengandung banyak gas yang membahayakan bagi kesehatan. Polusi udara yang sering kita alami sebagian besar dikarenakan oleh kendaraan bermotor dan asap rokok. Paparan gas seperti Karbon Monoksida (CO), Karbon Dioksida $\left(\mathrm{CO}_{2}\right)$, Nitrat Oksida (NO), Tar, Nikotin dari kendaraan bermotor dan asap rokok dapat menyebabkan munculnya berbagai penyakit pernapasan. Pada penelitian ini, sistem sensor gas elektrokimia tipe CO-B4 digunakan untuk mendeteksi CO dan NO-B4 digunakan untuk mendeteksi NO. Sensor ini dapat mendeteksi kadar gas yang rendah sehingga keluaran sensor yang sangat kecil ini sering terpendam oleh noise. Untuk itu diperlukan proses digital low pass filter (LPF) dengan frekuensi cutoff $5 \mathrm{~Hz}$ untuk menghilangkan noise. LPF diimplementasikan pada mikrokontroller Arduino Due. Hasil dari pembacaan sensor divisualisasikan pada LCD TFT. Sistem sensor gas elektrokimia ini telah digunakan untuk monitoring polusi udara di ruang terbuka seperti jalan raya.
\end{abstract}

Kata Kunci- Arduino Due, Liqiud Crystal Display Thin Film Transistor (LCD TFT), Low Pass Filter (LPF), Sensor Gas Elektrokimia

\section{PENDAHULUAN}

$P^{o}$ OLUSI udara di wilayah perkotaan besar di Indonesia beberapa tahun belakangan ini mempunyai kondisi yang sudah memprihatinkan. Udaranya telah dipenuhi oleh asap yang mengandung gas yang berbahaya bagi kesehatan. Salah satu pemicu utama dari kondisi tersebut adalah jumlah kendaraan bermotor. Sebagai sumber utama polusi udara di perkotaan, kendaraan bermotor telah meningkat jumlahnya dengan tajam dalam kurun waktu beberapa tahun terakhir. Pertumbuhan jumlah kendaraan bermotor selama satu tahun (2015-2016) mencapai 7 juta menurut data bada pusat statistik Indonesia (BPS), ditunjukkan pada Tabel 1.

Kendaraan bermotor mengeluarkan berbagai jenis gas maupun partikel yang terdiri dari berbagai senyawa anorganik dan organik dengan berat molekul yang besar yang dapat langsung terhirup melalui hidung seperti gas karbon monoksida (CO) dari kendaraan berbahan bakar

Tabel 1.

Perkembangan Jumlah Kendaraan Bermotor di Indonesia

\begin{tabular}{lrrrr}
\hline \hline \multirow{2}{*}{$\begin{array}{c}\text { Jenis Kendaraan } \\
\text { Bermotor }\end{array}$} & 2013 & 2014 & 2015 & 2016 \\
\hline Mobil Penumpang & 11484514 & 12599038 & 13480973 & 14580666 \\
Mobil Bis & 2286309 & 2398846 & 2420917 & 2486898 \\
Mobil Barang & 5615494 & 6235136 & 6611028 & 7063433 \\
Sepeda motor & 84732652 & 92976240 & 98881267 & 105150082 \\
Jumlah & 104118969 & 114209260 & 121394185 & 129281079 \\
\hline \hline
\end{tabular}

bensin dan gas Nitrat Oksida (NO) dari kendaraan berbahan bakar diesel. Selain polusi udara dikarenakan oleh kendaraan bermotor juga terdapat polusi udara dikarenakan asap rokok

Seperti yang sudah diketahui bersama bahwasannya rokok merupakan sesuatu hal yang sangat disukai oleh masyarakat di Indonesia. Banyak sekali orang di Indonesia ini yang merokok tanpa memikirkan resiko yang akan terjadi di masa yang akan datang. Asap rokok mengandung ribuan zat kimia yang mana komponen asap yang paling dikenal adalah tar, nikotin, dan $\mathrm{CO}$.

Polusi udara yang merupakan proses pencemaran pada udara ini tentu saja mempunyai berbagai dampak yang dapat kita rasakan. Dampak yang ditimbulkan oleh polusi udara ini tentu saja merupakan dampak yang bersifat negatif. Adapun dampak utama dari adanya polusi udara adalah gangguan pernafasan seperti misal gangguan paru- paru.

Berdasarkan referensi diatas, keberadaan $\mathrm{CO}$ dan $\mathrm{NO}$ pada udara dapat berbahaya bagi kesehatan manusia. Sehingga pada penelitian ini akan dibuat sistem sensor gas elektrokimia untuk mendeteksi CO dan NO yang ada pada polusi udara.

\section{METODE PENELITIAN}

Pada bab ini akan dibahas beberapa tahap perancangan sistem sensor gas elektrokimia, yaitu diagram blok sistem, hardware sensor gas, perancangan LPF, proses identifikasi gas.

\section{A. Diagram Blok Sistem}

Pada diagram blok sistem ini akan menjelaskan tentang sistem keseluruhan dari sistem sensor gas elektrokimia. Sistem sensor gas ini akan melakukan pemantauan kadar gas CO dan NO.

Seperti yang digambarkan pada Gambar 1, perancangan keseluruhan sistem akan berjalan seperti pada diagram blok tersebut. Diagram blok secara umum terdiri dari sampel gas uji sebagai masukan, ruang uji gas sebagai tempat pengujian gas, LPF sebagai pemroses sinyal dari sensor, dan visualisasi.

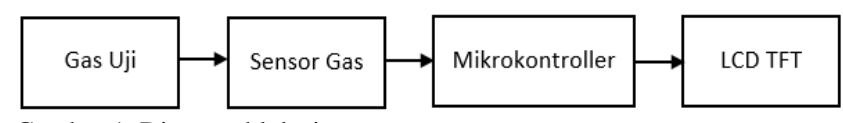

Gambar 1. Diagram blok sistem.

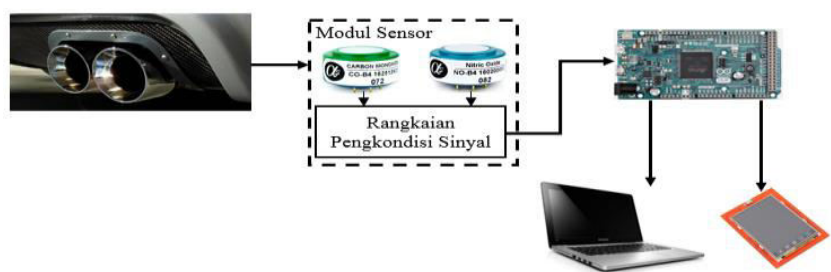

Gambar 2. Diagram blok perangkat keras. 
Perangkat keras pada sistem sensor gas elektrokimia terdiri dari :

1. Gas Uji

2. Sampel gas uji yang akan digunakan pada penelitian ini adalah gas sisa pembuangan kendaraan bermotor.

3. Modul Sensor Gas Elektrokimia

4. Sensor yang digunakan adalah sensor CO-B4 dan NO-B4, yang digunakan untuk membaca nilai gas $\mathrm{CO}$ dan NO.

5. Arduino Due

Arduino ini merupakan produk Arduino yang berbasis pada CPU Atmel SAM3X8E ARM CortexM3 [1][2]. Arduino Due pada penelitian ini digunakan untuk menghitung dan mengolah semua data dari sensor dan visualisasi.

6. LCD TFT

LCD TFT digunakan untuk visualisasi nilai dari sensor gas elektrokimia.

Sedangkan perangkat lunak dari sistem sensor gas elektrokimia secara umum adalah perangkat lunak pada mikrokontroler. Perangkat lunak yang dirancang ini berfungsi untuk melakukan proses pembacaan ADC, low pass filter dan visualisasi pada LCD TFT.

\section{B. Perancangan Perangkat Keras}

Pada Gambar 2 dapat dilihat diagram blok perangkat keras sistem sensor gas elektrokimia yang terdiri dari sensor gas elektrokimia yaitu CO-B4 dan NO-B4, ruang uji gas, rangkaian pengkondisi sinyal, pompa, buck converter, Arduino due, dan LCD TFT.

\section{1) Sensor Gas Elektrokimia}

Sensor gas CO-B4 dan NO-B4 pada penelitian ini digunakan untuk mendeteksi nilai karbon monoksida dan nitrat oksida. Sensor ini dipilih karena dapat mendeteksi gas yang spesifik dan mampu mendeteksi kadar gas yang rendah.

\section{2) Rangkaian Pengkondisi Sinyal}

Pada Gambar 3 merupakan contoh rangkaian pengkondisi sinyal sensor gas elektrokimia. Rangkaian ini berfungsi untuk mengaktifkan sensor dan mengubah arus menjadi tegangan. Pengubahan arus menjadi tegangan ini dikarenakan keluaran dari sensor gas ini adalah arus tetapi ADC dari Arduino Due hanya dapat membaca besaran tegangan.

\section{3) Ruang Uji Gas}

Diagram blok ruang uji gas dapat dilihat pada Gambar 4. Pada tahap ini terdapat pompa udara yang berfungsi menyalurkan udara ke ruang uji gas. Sebelum sampel gas masuk ke ruang uji gas, udara akan melawati silica gel yang berfungsi sebagai pengering udara agar udara yang akan diuji tidak mengandung air. Tujuan dari pengeringan udara ini agar hasil pengukuran bisa presisi dan valid.

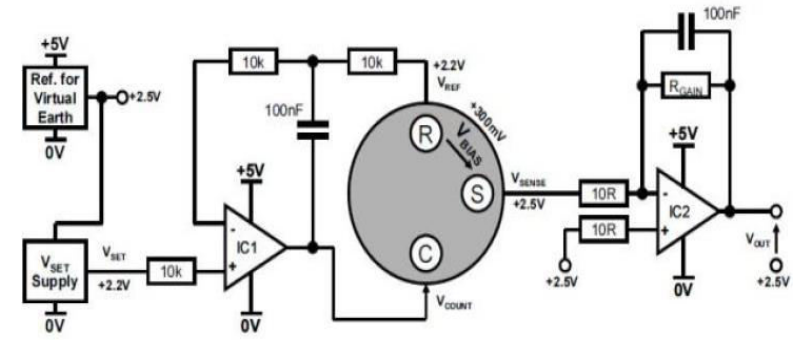

Gambar 3. Rangkain pengkondisi sinyal sensor gas elektrokimia dengan single supply [3].



Gambar 4. Diagram blok ruang uji gas

\section{4) Komputer}

Komputer pada penelitian ini digunakan sebagai interface dari sinyal dengan program delphi yang digunakan untuk melihat keluaran sensor yang sudah melalui proses LPF dan juga sinyal sensor gas asli (tanpa LPF).

\section{Perancangan Perangkat Lunak}

Pada Gambar 5 dapat dilihat diagram blok dari perangkat lunak sistem sensor gas elektrokimia. Pada bab ini perangkat lunak hanya menggunakan Arduino Due untuk melakukan proses ADC pada sensor, LPF, dan visualisasi.

1) ADC Sensor Gas Elektrokimia

Sensor gas elektrokimia memiliki nilai keluaran berupa ADC. Nilai ADC tersebut akan dikonversi ke dalam PPM, maka diperlukan data berupa Vout dari sensor gas $\mathrm{CO}$ dan NO. ADC tersebut nantinya diproses oleh arduino yang memiliki ADC 12 bit. Perhitungan tegangan ADC (Analog Digital Converter) dapat dirumuskan pada persamaan:

$$
\text { Tegangan } A D C=\frac{V_{\text {in }} \times 4095}{V_{\text {ref }}}
$$

2) Perangkat Lunak Low Pass Filter Butterworth Orde 2

Filter ini digunakan untuk meredam noise yang dihasilkan dari keluaran sensor [4]. Pada perangkat ini akan digunakan digital butterworth lowpass filter orde 2 untuk meredam noise. Jenis filter ini diturunkan berdasarkan persamaan filter analog sehingga lebih mudah dalam mengatur respon frekuensi dari filter tersebut [5]. Proses ini akan menggunakan filter dengan frekuensi cutoff $5 \mathrm{~Hz}$. Pada Gambar 6 menunjukkan alur keseluruhan dari sistem low pass filter

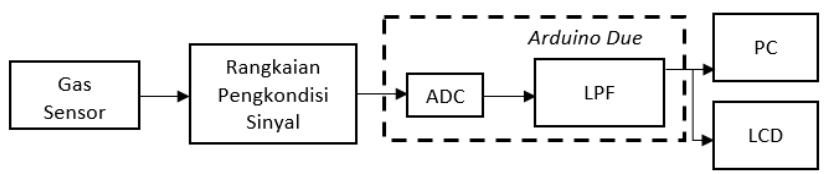

Gambar 5. Diagram blok perangkat lunak

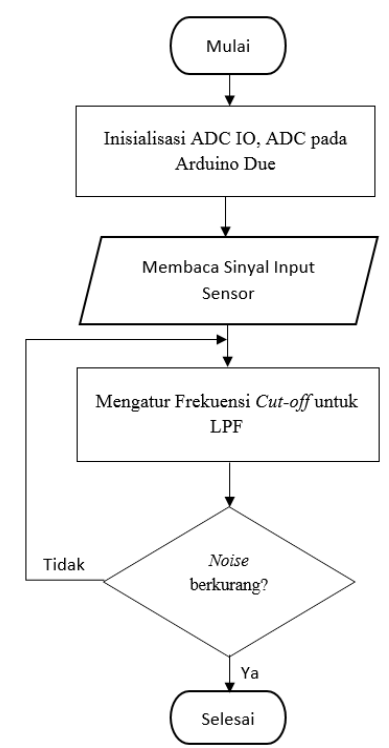

Gambar 6. Flowchart dari Low Pass Filter. 


\section{Kalibrasi Sensor Gas Elektrokimia}

Modul sensor gas CO-B4 merupakan salah satu jenis sensor gas elektrokimia yang mampu mendeteksi kandungan gas karbon monoksida di udara. Sensor CO-B4 memiliki 3 elektroda dan salah satunya merupakan elektroda work yang masuk ke rangkaian pengkondisi sinyal yang menghasilkan nilai yang digunakan sebagai input mikrokontroler Arduino Due. Nilai tegangan keluaran dari rangkaian pengkondisi sinyal CO-B4 dikonversi menjadi satuan part per million (ppm), sehingga diperlukan proses kalibrasi [10]. Proses kalibrasi ini memerlukan sensor CO-B4, rangkaian pengkondisi sinyal, Arduino Due, CO-meter, gas CO dari sisa pembuangan mobil, dan wadah untuk mempersempit ruangan agar gas $\mathrm{CO}$ tidak tercampur dengan gas lainnya. Proses kalibrasi sensor CO-B4 dilakukan seperti pada Gambar 7.

Arduino Due pada proses ini digunakan untuk membaca data berupa tegangan dari sensor dan CO-meter menampilkan data kadar gas dalam ppm pada wadah tertutup. Data tersebut akan dibandingkan untuk mendapatkan persamaan matematis perbandingan antara output dari sensor dan pembacaan pada CO-meter. Persamaan matematis dari pengujian tersebut diperoleh dengan menggunakan regresi polinomial.

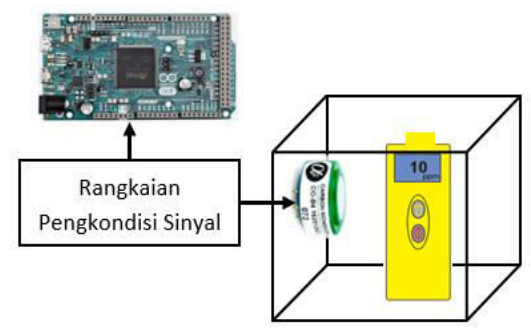

Gambar 7. Perancangan kalibrasi sensor CO.

\section{HASIL PENGUJIAN DAN ANALISA}

Setelah dilakukan perancangan perangkat sistem sensor gas elektrokimia, maka akan dilakukan serangkaian uji coba alat sesuai dengan kinerja yang diharapkan. Hasil dari perancangan dan pembuatan perangkat keras sistem sensor gas ditunjukkan pada Gambar 8. Perangkat ini terdiri dari silika gel yang berfusngi untuk menyaring udara [11], sensor, ruang uji gas dan rangkaian pengkondisi sinyal untuk menguji kadar gas, pompa, power supply, dan rangkain buck converter yang digunakan untuk menarik udara yang ada pada ruang uji gas dan sampel gas. Arduino due sebagai mikrokontroller yang digunakan untuk sistem LPF dan visualiasasi pada LCD TFT.

\section{A. Pengujian Sensor Gas dan Software}

Pada pengujian ini akan dilakukan pengujian sensor gas dan software yang telah dibuat. Pada pengujian sensor ini, ruang gas akan diberikan sampel gas untuk melihat respon dari sensor, seperti yang ditunjukkan pada Gambar 9. Kemudian sensor yang terhubung dengan rangkaian pengkondisi sinyal akan mengeluarkan tegangan dan dibaca oleh Arduino. Pada Arduino terdapat program LPF digital yang digunakan untuk menghilangkan noise dan juga digunakan komunikasi serial agar data dapat disimpan. Dalam hal ini, data disimpan dalam bentuk CSV. Gambar 10 menunjukkan hasil interface yang merupakan tampilan respon sensor pada komputer.



Gambar 8. Realisasi perangkat keras sistem sensor gas elektrokimia.

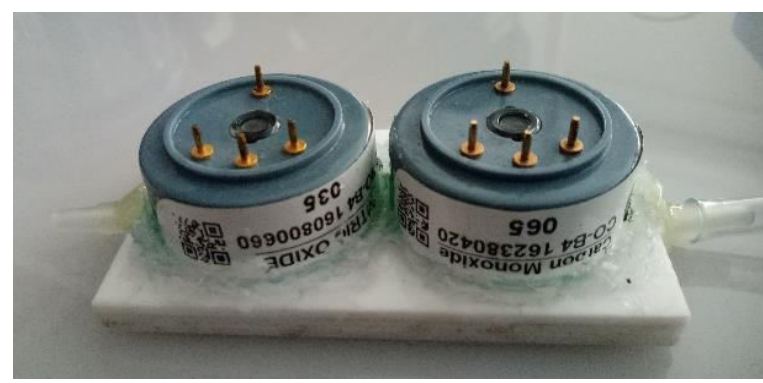

Gambar 9. Realisasi ruang uji gas.

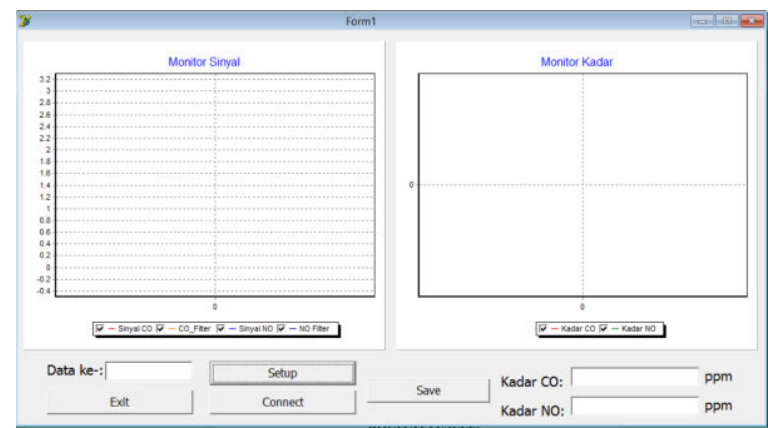

Gambar 10. Interface pada computer.



Gambar 11. Pengujian respon sensor CO.

NO

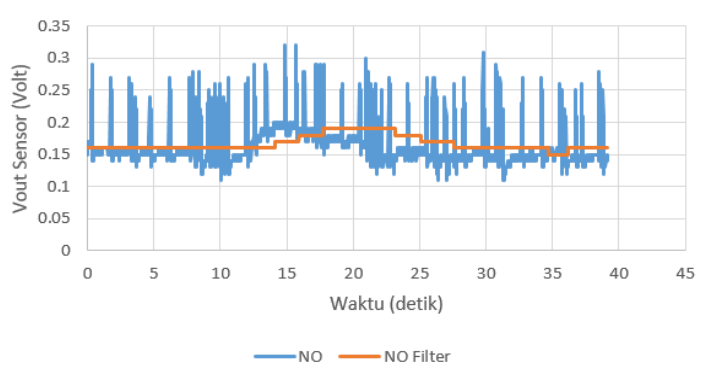

Gambar 12. Pengujian respon sensor NO. 


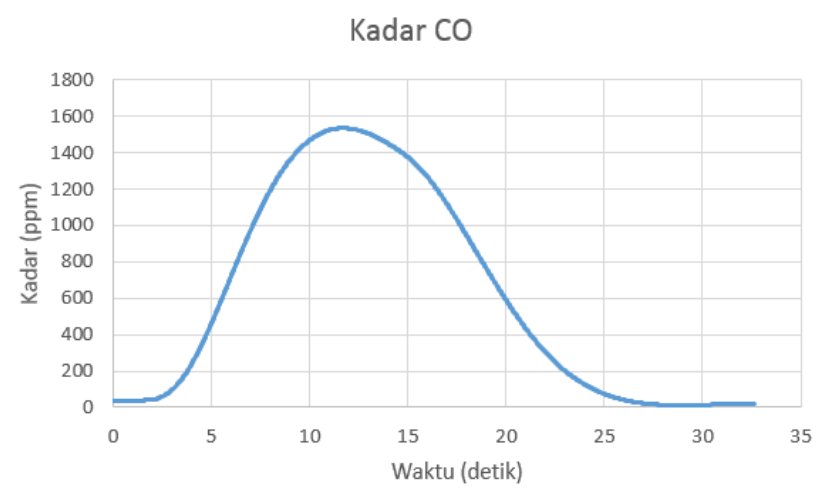

Gambar 13. Hasil kadar gas CO.

Kadar NO



Gambar 14. Hasil kadar gas NO.

Gambar 11, 12, 13, dan 14 merupakan hasil pengujian respon sensor terhadap gas CO dan NO. Pada Gambar 11 dan 12, ruang gas uji diberi sisa gas dari kendaraan bermotor dan dapat dilihat bahwa respon dari sensor menaik saat gas dimasukkan dan respon dari sensor akan menurun saat gas dikeluarkan menggunakan pompa. Sedangkan pada Gambar 13 dan 14 menunjukkan kadar dari masing-masing gas yang dibaca oleh sensor. Sinyal ini diperoleh dari sinyal asli keluaran dari sensor yang sudah diproses melewati digital LPF pada Arduino Due.

\section{B. Kalibrasi Sensor}

Untuk melakukan proses kalibrasi, sensor dan CO meter dimasukkan kedalam wadah untuk mempersempit ruang dan mempermudah untuk pendeteksian gas seperti yang ditunjukkan pada gambar 15. Percobaan ini dilakukan sebanyak 3 kali yang hasilnya ditunjukkan pada Tabel 2.

Tabel 2.

\begin{tabular}{cc}
\multicolumn{2}{c}{ Kalibrasi Sensor CO-B4 dengan CO mete } \\
\hline \hline CO meter (ppm) & V Out (V) \\
\hline 125 & 2.1815 \\
120 & 2.13 \\
110 & 2.0505 \\
100 & 1.917 \\
90 & 1.871 \\
80 & 1.7565 \\
70 & 1.7105 \\
60 & 1.7085 \\
50 & 1.683 \\
40 & 1.605 \\
30 & 1.5765 \\
20 & 1.5355 \\
10 & 1.4935 \\
5 & 1.467 \\
0 & 0.7625 \\
\hline
\end{tabular}



Gambar 15. Kalibrasi sensor CO-B4 dengan CO meter.

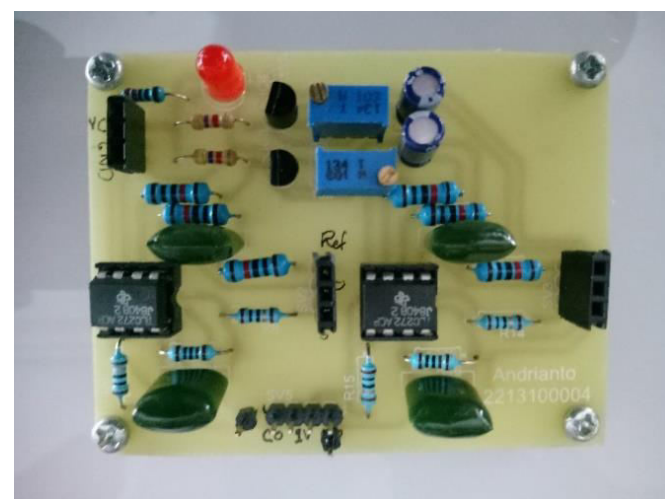

Gambar 16. Rangkaian pengkondisi sinyal sensor.

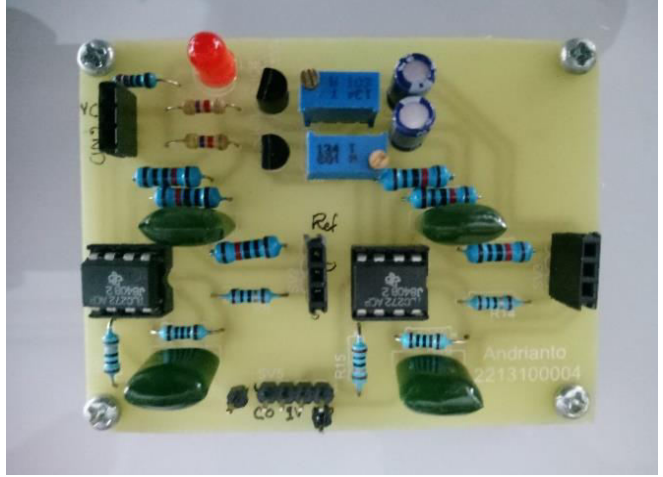

Gambar 16. Rangkaian pengkondisi sinyal sensor.

\section{Rangkaian Pengkondisi Sinyal}

Gambar 16 menunjukkan hasil desain rangkaian pengkondisi sinyal yang dibutuhkan untuk mendapatkan sinyal sensor dalam besaran tegangan. Rangkaian ini terdiri dari regulator LM336-2.5 dan IC Operational Amplifier TLC272.

\section{Pengujian Sistem}

Pada pengujian ini dilakukan dengan cara mengambil sampel udara di jalan raya. Untuk itu perlu dipersiapkan alat-alat untuk mengambil sampel gas, yaitu pompa untuk menyedot gas polusi, selang sebagai penghubung, powerbank sebagai supply untuk menyalakan pompa, dan kantong gas untuk tempat penampungan gas polusi. Pertama-tama gas diambil menggunkan pompa untuk menyedot dan dimasukkan ke dalam kantong gas seperti yang ditunjukkan pada Gambar 17. Kemudian gas tersebut dipompa untuk dimasukkan ke ruang uji gas agar dapat dibaca oleh sensor. Data tersebut kemudian diproses oleh Arduino Due dan divisualisasikan pada LCD TFT. Selain 
itu, data dikirim secara serial dan di-interface-kan pada komputer untuk disimpan dalam format CSV.

Percobaan dilakukan sebanyak 3 kali. Data diambil pada hari Sabtu 23 Juni dan Minggu 24 Juni di jalan Manyar Kertoarjo, Surabaya. Pengambilan data yang pertama pada hari Sabtu jam 11.00. Pengisian kantong gas dilakukan selama 2 menit dimana kantong gas sudah penuh. Kemudian gas dari kantong sampel tersebut dimasukkan ke ruang uji untuk diukur kadar dari gas tersebut yang ditunjukkan pada Gambar 18 dan 19.



Gambar 17. Pengambilan sampel polusi udara di jalan raya

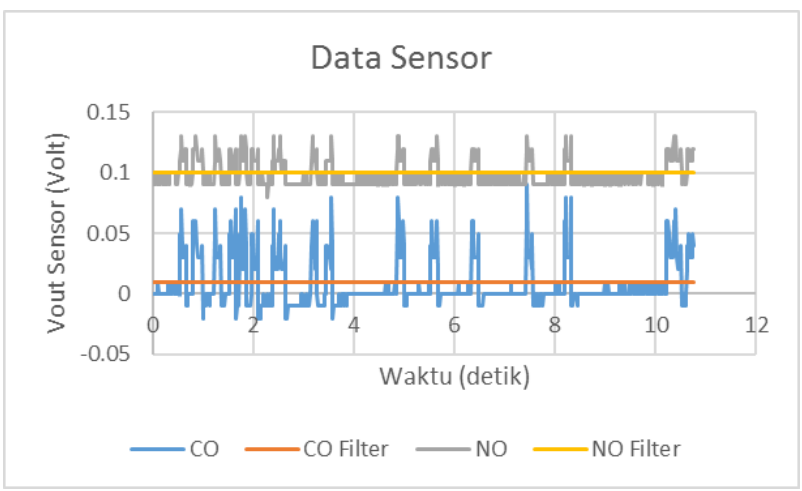

Gambar 18. Data sensor terhadap polusi udara Sabtu 23 Juni jam 11.00

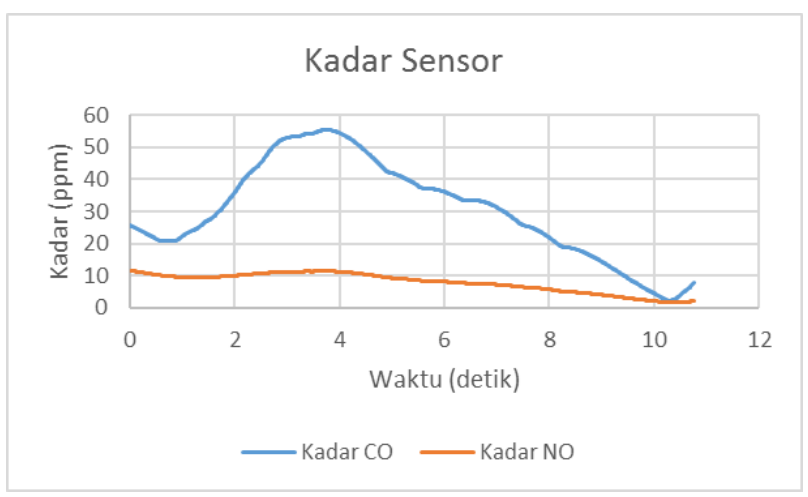

Gambar 19. Kadar polusi udara Sabtu 23 Juni jam 11.00

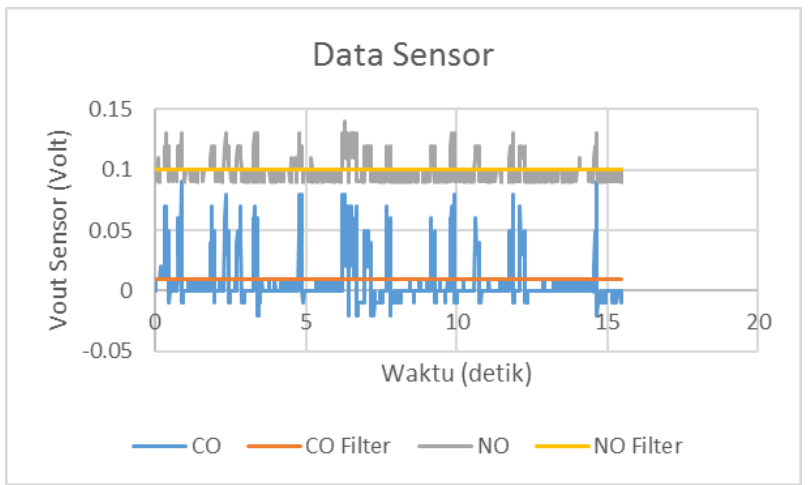

Gambar 20. Data sensor terhadap polusi udara Sabtu 23 Juni jam 18.00

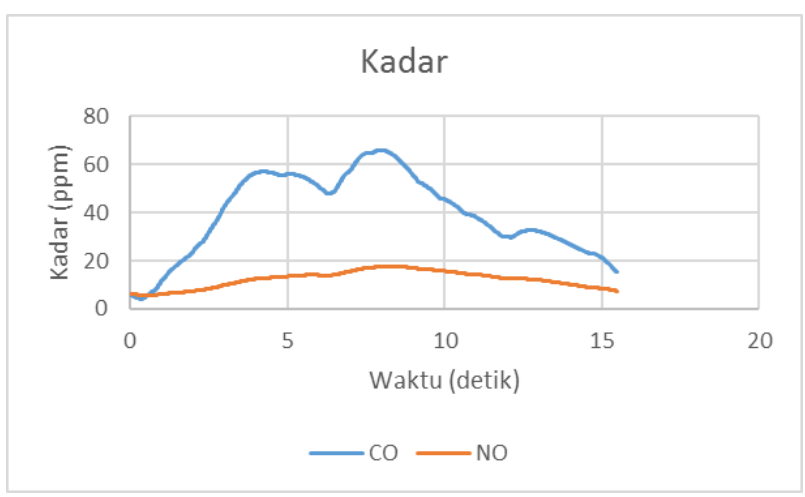

Gambar 21. Kadar polusi udara Sabtu 23 Juni jam 18.00

Percobaan kedua dilakukan pada hari Sabtu jam 18.00 dengan data yang ditunjukkan pada Gambar 20 dan 21. Pengujian terakhir dilakukan pada hari Minggu 24 Juni jam 15.00 dengan data yang ditunjukkan pada Gambar 22, 23, dan 24.

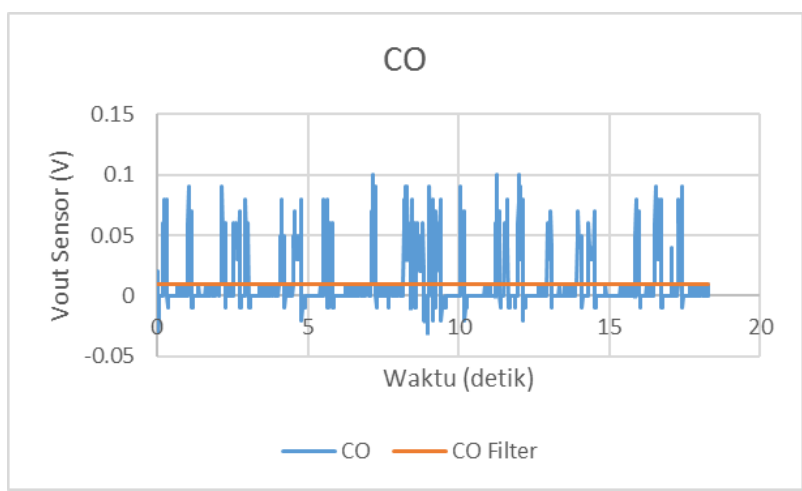

Gambar 22. Data sensor terhadap polusi udara CO Minggu 24 Jun jam 15.00

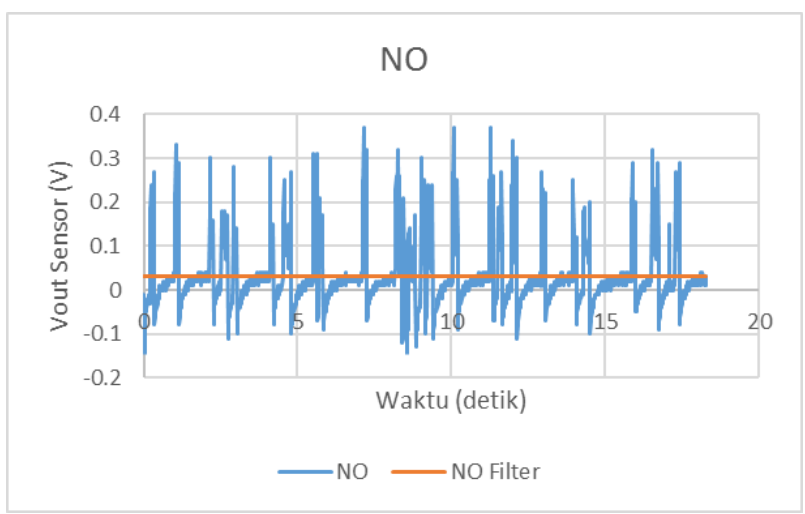

Gambar 23. Data sensor terhadap polusi udara NO Minggu 24 Juni jam 15.00 


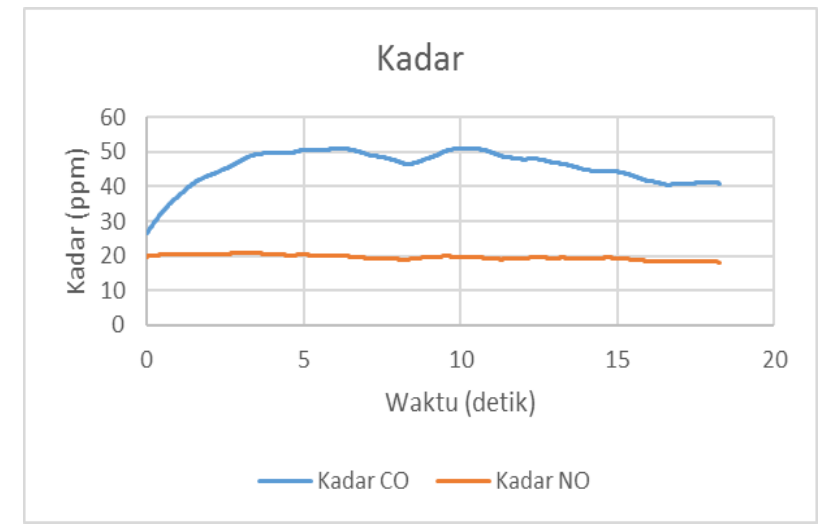

Gambar 24. Kadar polusi udara Minggu 24 Juni jam 15.00

Rerata nilai kadar gas polusi udara ditunjukkan pada Tabel 3. Dapat dilihat adanya perbedaan kadar gas $\mathrm{CO}$ dan $\mathrm{NO}$ pada setiap waktu. Hal ini dikarenakan jumlah kendaraan bermotor yang melintas pada jalan tersebut berbeda-beda.

Tabel 3.

Kadar gas polusi udara

\begin{tabular}{cccc}
\hline \hline Hari & Jam & $\begin{array}{c}\text { Kadar CO } \\
(\mathrm{ppm})\end{array}$ & $\begin{array}{c}\text { Kadar NO } \\
(\mathrm{ppm})\end{array}$ \\
\hline Sabtu & 11.00 & 30,47 & 7,89 \\
Sabtu & 18.00 & 39,65 & 12,25 \\
Minggu & 15.00 & 45,84 & 19,64 \\
\hline \hline
\end{tabular}

\section{KESIMPULAN}

Berdasarkan hasil pengujian yang telah dilakukan, dapat disimpulkan bahwa untuk mendeteksi gas karbon monoksida dan nitrat oksida dapat digunakan sensor CO-B4 dan NOB4. Sistem digital Low Pass Filter (LPF) Butterworth dengan frekuensi cutoff $5 \mathrm{~Hz}$ dapat digunakan untuk menghilangkan noise. Sistem LPF dapat diimplementasikan menggunakan Arduino Due sebagai mikrokontroller dari sistem sensor gas elektrokimia. Sistem sensor gas elektrokimia ini dapat digunakan untuk monitoring polusi udara di Surabaya dengan rata-rata kadar gas CO 38,65 ppm dan NO 13,26 ppm.

\section{DAFTAR PUSTAKA}

[1] Schafer and Buck, "Discrete-Time Signal Processing in RF Application, Lecture handout: Digital Signal Processing," Villigen, 2007.

[2] S. Setiawan, "Studi Eksperimental Fuzzy FES Control untuk Pergerakan Knee Joint," 2016.

[3] M. Gumelar, M. Rivai, and Tasripan, "Rancang Bangun Wireless Electronic Nose Berbasis Teknologi Internet of Things," J. Tek. ITS, 2017.

[4] F. Rizki and M. Rivai, "Autonomous Surface Vehicle sebagai Alat Pemantau Lingkungan Menggunakan Metode Navigasi Waypoint," J. Tek. ITS, 2018.

[5] H. Rahmannuri, M. Rivai, and T. A. Sardjono, "Design of Digital Lock-In Amplifier for Low Concentration Gas Detection," in International Seminar on Intelligent Technology and Its Application (ISITIA), 2017. 